\title{
A SPATIOTEMPORAL ANALYSIS OF URBAN DENSIFICATION IN AN ORGANICALLY GROWING URBAN AREA
}

\author{
Jibrin Katun MOHAMMED ${ }^{1}$, Aremu Olanrewaju SULYMAN², \\ Abdullahi Alhaji ALIYU ${ }^{3}$ \\ ${ }^{1}$ Department of Estate Management and Valuation, Federal Polytechnic, Bida, Nigeria \\ ${ }^{2}$ Department of Urban and Regional Planning, Federal University of Technology, \\ Minna, Nigeria \\ ${ }^{3}$ Department of Urban and Regional Planning, Federal Polytechnic, Bida, Nigeria
}

Corresponding author's e-mail: jibrinkatun@gmail.com

\begin{abstract}
Urban densification has attracted much attention in recent times, particularly in addressing certain urban problems such as urban sprawl and promoting compact development, though problems of unplanned densification are yet to be addressed in the literature. This paper examines space and time dynamics of urban densification, where patterns and changes in the residential densification of Bida urban area in Nigeria are assessed. The study relied on point features representing buildings for the years 2008, 2013, and 2018 digitized using ArcGIS 10.6. The data were analysed using Point Density spatial method to develop the spatiotemporal models which were further reclassified into three categories: low, medium, and high densities, respectively. The paper has found out that residential densities increase along the urban-rural gradient with clear evidence for unplanned urban densification as a result of the organic growth. Therefore, there is the need for planned densification in urban development which can curb the increasing residential density that reduces green and open spaces.
\end{abstract}

Keywords: Densification, organic growth, spatiotemporal analysis, urban area.

\section{INTRODUCTION}

Urban densification is the increase in urbanisation level of a limited area, which has an adverse effect on the biodiversity of its green spaces by destroying the habitats, disintegration, and soil temperature increase or pollutions (Vergnes et al., 2014). Urban densification causes a lot of challenges to cities ranging from a decline in housing affordability, and infrastructural provisions, and difficulties of city management. Urban densification as the second phase of urbanisation has a consequential effect on affordable housing and may cause a change in the housing market. As a result of a change in the housing market, the entire city or national economy could experience a shift either negatively or positively (Gulyani et al., 2018).

Bida urban area in Nigeria, like other urban areas of the developing world, is characterised by rapid urban growth which is largely uncontrolled, and increased urban densification especially in the core areas of the town. As the population 
increases, the building development increases leading to unguided conversion in the use of structure and landscape. For example, commercial and special structures are converted to residential units or industrial buildings converted to commercial uses; green spaces are encroached, low-rise buildings are converted to high-rise structures, and river banks and flood plains developed to increase housing stock. Although most urban structures conform with Alonso's monocentric urban structure, some are not (Mohammed \& Sulyman, 2019).

Urban densification has generated a lot of discussions among scholars (Amer et al., 2017; Chandrabose et al., 2019; Chhipi-Shrestha et al., 2017; Curie et al., 2010; de Oliveira e Sousa \& Celani, 2018; Haaland \& van den Bosch, 2015; Schmidt-Thomé et al., 2013; Treija et al., 2018; Wang et al., 2019). For example, urban densification is conceived as an urban regeneration method (Broitman \& Koomen, 2015; 2019). Treija, Bratuškins, and Korolova (2018) considered it as an infill development approach in a large housing area. Vuckovic et al. (2019) see it as heat island mitigation for the improvement of outdoor thermal conditions where it was argued that vertical extensions of existing buildings provided solar shielding. Urban densification may be protective against obesity risk but may have adverse effects on blood lipids and blood pressure (Chandrabose et al., 2019).

In contrast, urban densification has negative impact on housing demand and land use (Wolff et al., 2017). In terms of temperature, it contributes to urban heat islands (Duan et al., 2019; Vuckovic et al., 2019) which should be discouraged in a hot and humid climate (Lima et al., 2019; Ribault et al., 2017). Considering urban open and green spaces, urban densification has contributed to potential changes in green space infrastructure (Lin et al., 2015; Ståhle, 2008; Vergnes et al., 2014). It also leads to the loss of public and private urban open and green spaces (Haaland \& van den Bosch, 2015; Kyttä et al., 2013). Urban densification policy also leads to the privatisation of public open spaces (Treija et al., 2018). Ghadami \& Newman (2019) suggests that urban densification policies change the urban spatial structure.

From previous studies, urban densification is conceived as a planning approach to promote the implementation of the compact city that discourages urban sprawl, which is referred to as planned densification. However, attention is not given to unplanned densification where many less developed cities like Bida continue to grow densely without a definite policy or programmes for such activities. This is another vast unexplored area that needs attention, particularly in urban morphological studies. It is on this backdrop the study attempts to examine the space and time dynamics of urban densification in the Bida urban area.

The main questions addressed in this study are: What is the pattern of urban densification between 2008 and 2018 and what is extent of the changes? The main goal of this paper is to examine the spatiotemporal dynamics of urban densification in an organically growing urban area in order to provide spatial information on illuminating changes in the urban structure, while the specific objectives are to examine the pattern of residential densification considering Alonso's monocentric model, and to examine the changes in the residential densification of the study area over time.

The outcomes of this study will help urban managers and authorities to efficiently solve the problem of spatial growth and management. 


\section{LITERATURE REVIEW}

\subsection{Monocentric Model of Alonso}

The monocentric model has its root from Von Thünen's study on agricultural land use which became the centerpiece of Alonso's (1964) models of urban economics, particularly the residential location and the urban housing markets (Waddell, 2000). Transition from agriculture to urban environments, absolute and differential concepts received proper modifications. Alonso adapted and considered the Von Thünen model to an urban environment (Fujita, 1989). The input of Alonso in the model brought about the specific urban application, disparaging the notion that limited it to transport costs as an expression of impedance of space and preference for more central locations known as Bid Rent (Fujita, 2010). Similarly, Alonso's assumption includes competition among various economic activities, which are spatially distributed in the urban area based on their availability to pay rent, as locational determinants and choices and consequential value distributions (Manganelli \& Murgante, 2017).

Alonso took an exceptional position similar to preceding pioneers of urban economics and it was one of the fundamentals of his model (Ahlfeldt, 2011). Decreasing density gradients are a feature of these monocentric models, i.e., housing density decreases as distance to the CBD increases (Magliocca et al., 2011). The model was later extended by Muth and Mills where housing was added to the model (Gwamna et al., 2015). Although Muth and Mills have separate work, the monocentric city model of this version is referred to as the "Muth-Mills" model. In this version of the model, residential density, building heights, and population density all decline with distance from the CBD (Gwamna et al., 2015).

Combining Alonso's model and 'Muth-Mills' extension, the monocentric model suggests that moving towards the CBD, land for housing is more expensive, this encourages housing developers to build more apartments per unit of land to economise the space used, that is by developing small apartments of high-rise buildings, as the building height increases the cost of additional meters (Kulish et al., 2012). Then the choice of households would be either to reside in a better location, but more expensive and smaller apartment or in a far distant, but less expensive and bigger apartment towards the urban fringe (Kulish et al., 2012). According to the model, the urban form is characterised by taller buildings and higher density near the CBD, lower building height and lower density on the fringe. Total size of the urban area will simultaneously determine by the transportation cost, population size, and the land value in different uses, such as agriculture (Kulish et al., 2012).

The limitations of the monocentric concept that predicts the land and house prices are well known and have attracted large criticism (Ahlfeldt, 2011; Kulish et al., 2012). The monocentric model excludes non-transportation elements, which include instances in which humans prefer a choice of a residential location not primarily considering the commuting cost minimisation to their workplace. Besides, as the central areas of the city are under restructuring, and employment centres exist in the suburb, studies proved that the distance to the CBD would have less effect and become insignificant or/and irrelevant (Xiao, 2017). However, the 
model cannot be completely ruled out because it is still applicable to some extent in most urban studies such as housing density and population density. This is due to the centralised structure of most urban forms of developing countries.

\subsection{Urban Densification}

The ongoing debate over the environmental sustainability of different urban forms is both high profile and contentious. In the context of urban planning (of the Global North) the discussion however seems to be primarily focused on the issue of densification (Schmidt-Thomé et al., 2013). Several policies promote urban densification (i.e., compact city form creation or the densification of existing cities) to achieve a reduction in urban sprawl. Urban densification denotes an upsurge in the urbanisation level of a limited area, which could have a negative impact on the urban green space biodiversity through habitat destruction, pollution or would increase soil temperature, fragmentation, and alteration of socio-spatial structure (Vergnes et al., 2014). However, urban densification is also viewed as a problemsolving approach (Leffers \& Ballamingie, 2013).

There are three basic concepts - density, perceived density, and crowding used by urban managers to address the issue of how density affects people's lives (Alexander, 1993). Density describes the relationship between a given physical area and the number of objects in that area (Medayese et al., 2015). Density has an intrinsic relationship with urban morphology; it plays an important role in the shaping of urban forms. One of the pioneer planners Ebenezer Howard pointed out that the countryside had less density and a greener environment compared to the growing industrial city (Medayese et al., 2015). Alonso suggested that density increases when moving closer to the city centre and distance away from the city centre causes a decrease in density (Alonso, 1964). Density refers to both population density and housing density, which result from rapid urbanisation.

More recently, studies have shown that compact development provides solutions to many urban problems such as reducing urban sprawl and infrastructure provision (Broitman \& Koomen, 2015; Chhipi-Shrestha et al., 2017; Vergnes et al., 2014). This results in many compact cities in Europe and the Americas (Medayese et al., 2015). However, considering Howard's and Alonso's thoughts and the recent compact development that changes urban morphology, urban densification can be planned (deliberate) and unplanned (not deliberate). Therefore, urban densification can be divided into two categories: planned urban densification and unplanned urban densification.

Measuring urban density has been a problem for many researchers (Ståhle, 2008). Broitman and Koomen (2015) measured residential densification using a high level of detail spatial data that covered the Netherlands. They described land use by employing $100 \mathrm{~m}$ resolution rasterised data, residential density, and local explanatory variables of a wide range. Predominant land use was accessible for each cell for the years 2000 and 2010, which depended on an accumulated arrangement of spatially explicit land-use database of Netherlands Statistics. Wang et al. (2019) generated a land-use transition of 2001 to 2011 matrix using land-use maps with the aid of ArcGIS and examined the spatial and temporal urban density changes. The study employed various metrics based on the landscape to describe urban 
spatial pattern changes and to evaluate the model error nature. Analysis based on rings was adopted, which was primarily based on the classical urban theory. The analysis was employed to show transition of urban densification characteristics. The Land Transformation Model (LTM), which is a function of Artificial Neural Networks (ANNs) and GIS, was applied to simulate the changes in land use, which also utilised a raster modelling environment in urban growth simulation that relied on several bio-physical and socioeconomic factors. Relying on changes in the historical land use data and predictor variables, the ANN learns urban densification patterns; this information is then kept and applied to predict changes of future urban densification.

In contrast, Jiao (2015) acquired high-quality Landsat TM/ETM+ images, where the images were classified using the Maximum Likelihood Classification method in ENVI 4.5. The results from image classification were processed using a non-linear least-squares method to fit the proposed urban land density functions and a nonlinear function to the observed data by refining the parameters in successive iterations. They employed a trust-region algorithm in their study. They fit the urban land density functions with Matlab. Urban densification was also measured using microclimate simulations with different models. The results were compared, and uncertainty ranges were documented by testing the impact of urban fabric on the current climate (Loibl et al., 2019). Shahtahmassebi et al. (2016) developed a framework for measuring urban densification using time series of impervious surface fractions (ISFs) derived from remotely sensed imagery.

Predicting urban densification, Wang et al. (2019) documented past urban densification patterns and used the information to predict future densification trends in Southeastern Wisconsin. In another perspective, Delmelle et al. (2014) examined the socio-economic transformations that had occurred over a period of time as a result of urban densification programmes. In terms of risk assessment, León Canales et al. (2019) perceived that tsunami risk could increase due to urban densification. Urban densification programmes were also linked to mobility (de Oliveira e Sousa \& Celani, 2018).

Amer et al. (2017) examined urban densification through roof stacking where the systematic approach of three consecutive levels (urban, social, and engineering) was considered. Identification of multiple criteria was carried out to map and assess the potential of roof stacking as regards several added floors and location. Using ArcGIS software, maps were produced for roof stacking of Brussels at the city scale, which signified potential urban densification.

In a different perspective, Delmelle, Zhou, and Thill (2014) assessed urban densification using current land and real estate property records and reconstituted the urban map of Charlotte using World War II as a starting point. Ghadami and Newman (2019) used the Hot Spot approach based on the Getis Ord Local G statistical test and Arc GIS 10.2 to investigate the effect of the urban densification policies made after the Islamic Revolution on the urban spatial structure of Tehran. Vuckovic et al. (2019) simulated urban microclimate for both pre- and postdensification scenarios where the Rhinoceros 3D (parametric modelling environment) was considered and Grasshopper was used for built-in algorithms in the Rhino's plug-in. 


\section{METHODOLOGY}

\subsection{Study Area}

The study area is Bida town, a traditional north-central town of Nigeria located on latitude $9^{\circ} 5^{\prime} 0^{\prime \prime}$ North and longitude $6^{\circ} 1^{\prime} 0^{\prime \prime}$ East (Fig. 1). The town is the second largest settlement in the Niger State of Nigeria with a total built-up area of $67.45 \mathrm{~km}^{2}$ and about 255008 population based on the last national population census (Mohammed \& Sulyman, 2019).

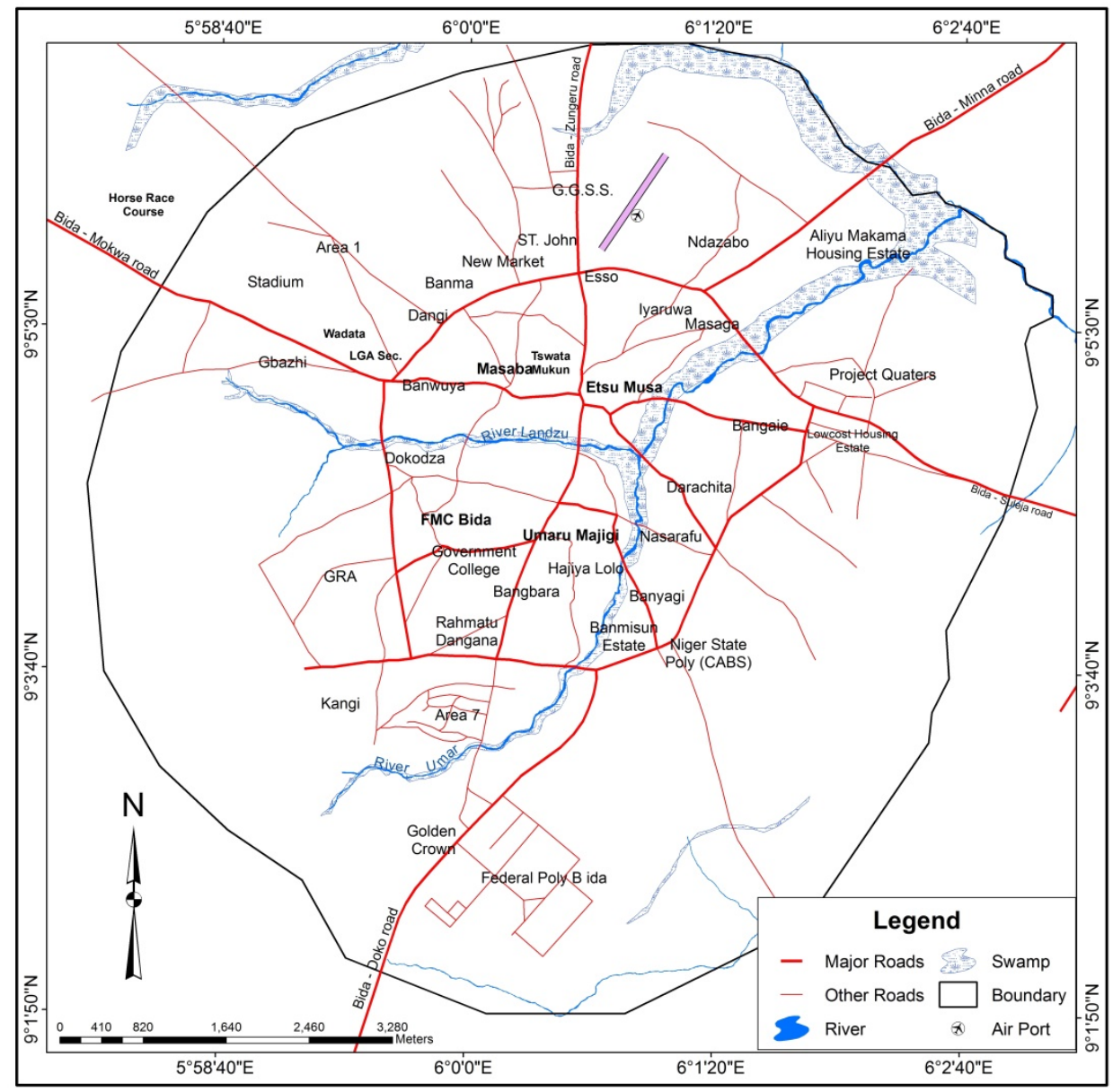

Fig. 1. Map of Bida (Field survey, 2020).

\subsection{Data}

Data needed for this research included satellite imageries which were captured for three different periods, i.e., 2008, 2013, and 2018 using maximum resolutions on the Google Earth application. The choice of Google Earth is due to its userfriendliness and availability of historical images. The satellite images were georeferenced where a vector approach was adopted in digitising all the buildings using point features in the ArcGIS environment. The entire buildings for each year under study were represented by points (Fig. 2). 


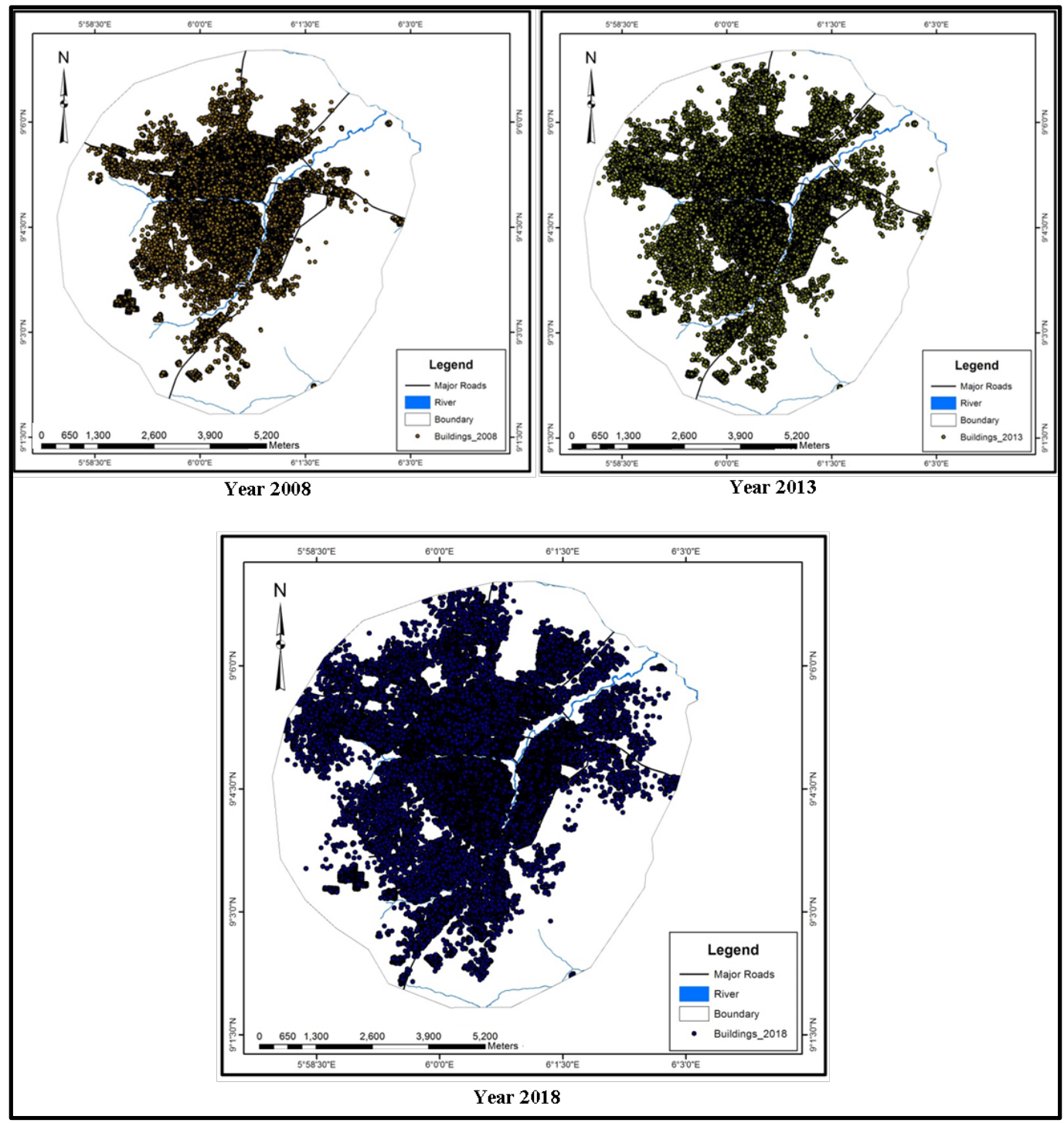

Fig. 2. Location of buildings in the study area for the year 2008, 2013 and 2018 (Field survey, 2020).

\subsection{Analysis}

The point density spatial analyst tool of ArcGIS 10.6 was used to analyse the residential density of the study area for the years under study. Point density produces a raster showing a magnitude per unit area from point features that fall within a neighbourhood around each cell. Only the points that fall within the neighbourhood are considered when calculating the density. If no points fall within the neighbourhood at a particular cell, that cell is assigned NoData. Points used in the spatial model represent the location of buildings in the study area. The spatial analyses were extended to reach the boundary. The geo-pressing procedure produces raster files for the densities for the years 2008, 2013, and 2018. This is adopted where 'buildings within a fixed distance $d$ from $i$ ' are calculated in ArcGIS by using the 'Point Density' tool. This model was chosen for the benefit of better 
performance and visualization. The radius used for searching the neighbouring points $d=0.002672 \mathrm{~m}$ was chosen according to the content of the data.

The point density raster model outputs were further reclassified into three categories: low, medium, and high densities, respectively, using the Reclassify tool of the ArcGIS toolbox. This allowed for better representation of the three density level changes during the study period. The reclassified raster data set was also converted to polygon to allow for area measurement of each category, and the area covered by the polygonal shapes was measured in $\mathrm{km}^{2}$ using the Calculate Geometry tool of the ArcGIS.

\section{FINDINGS}

\subsection{The Pattern of Residential Densification}

The spatial approach was adopted to analyse the urban densification of the study area between 2008 and 2018. The spatial and temporal approach depicts the patterns of densification in a better morphological structure (Figs. 3-5).

Figure 3 shows spatial variations in residential densities of Bida in the year 2008. The result depicts the urban form in terms of residential density in that year. The structure of the town shows that areas around the Central Business District (CBD) are of high density while locations within the urban fringe tend to have lower residential densities. This is remarkable and relates to the fact that urban fringe locations during this period are outside the development zones. This result did not deviate from the traditional monocentric model of Alonso, which is consistent with many cities of the developing world, where density gradient decreases towards the urban fringe (Broitman \& Koomen, 2015).

As urban densification proceeded in an uncontrolled and unstructured manner, the spatial pattern of urban residential densities increased unevenly in 2013 (Fig. 4). The result shows that the residential density gradient increases towards the urban fringe without decreasing density in the CBD. The morphological structure of the town was retained in its traditional monocentric form, but towards the north and north-western part of the town, the residential density increased prominently.

Figure 5 shows that there was consistent and fast increasing residential density in the study area in 2018. Residential density increases during this period towards the north, west, and southern part of the town. However, the result implies that the western part had a low level of residential development. 


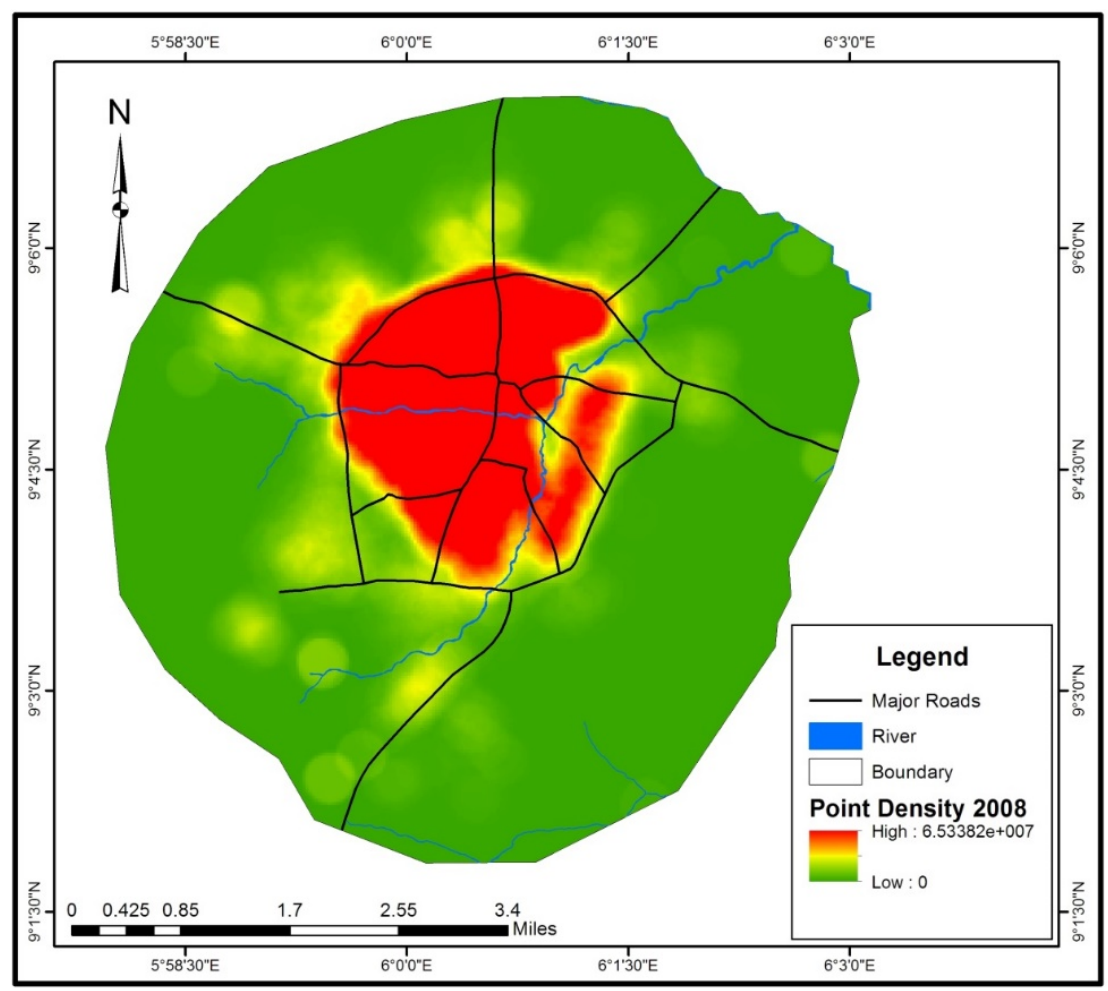

Fig. 3. Spatial pattern of residential density in the study area in 2008 (Developed by the authors, 2020).

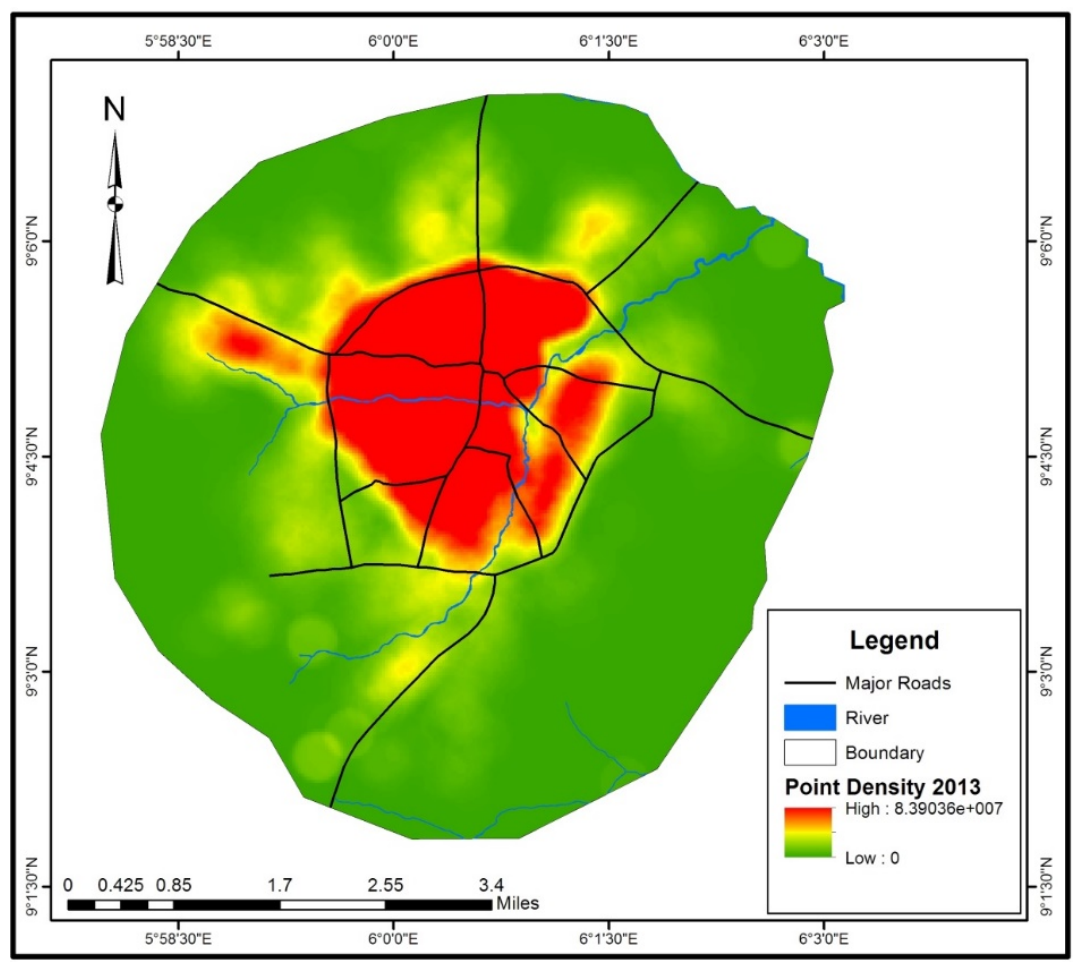

Fig. 4. Spatial pattern of residential density in the study area in 2013 (Developed by the authors, 2020). 


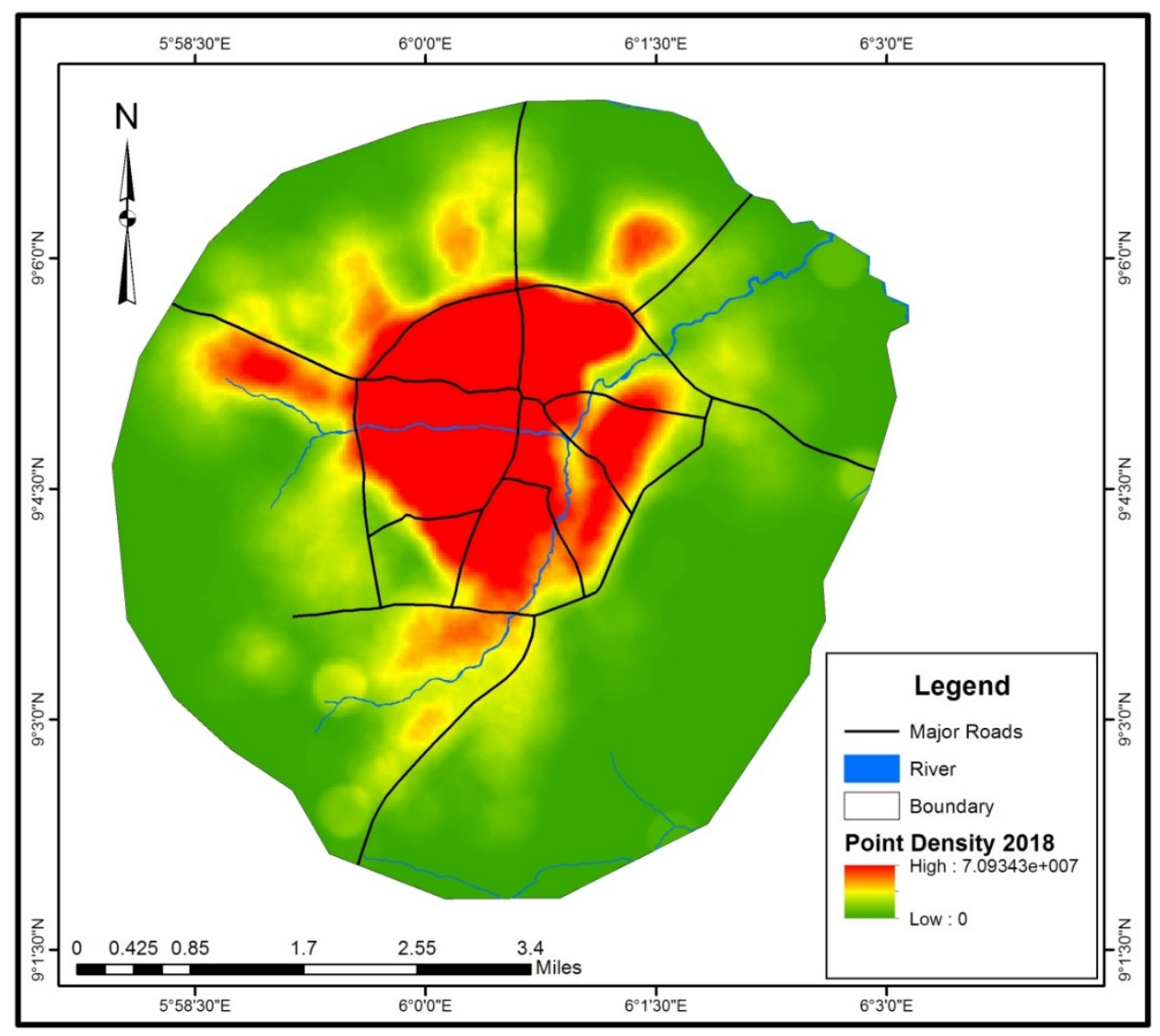

Fig. 5. Spatial pattern of residential density in the study area in 2018 (Developed by the authors, 2020).

\subsection{Changes in the Residential Densification}

The transition in the residential densification for 2008, 2013, and 2018, which was based on three major density classifications - high, medium, and low densities -, was measured in $\mathrm{km}^{2}$ according to the area coverage of each density level. It can be observed from Figs. 6-8 that densification transition in the study area depicts low to medium and to high-density residential areas, where high residential density overtook the medium and low-density residential areas. The results show that high density continues to spread without development control to the urban fringe. This is an indication of organic urban transformation, which lacks policy guidance and control and it is argued that it represents a form of unplanned or uncontrolled urban densification. 


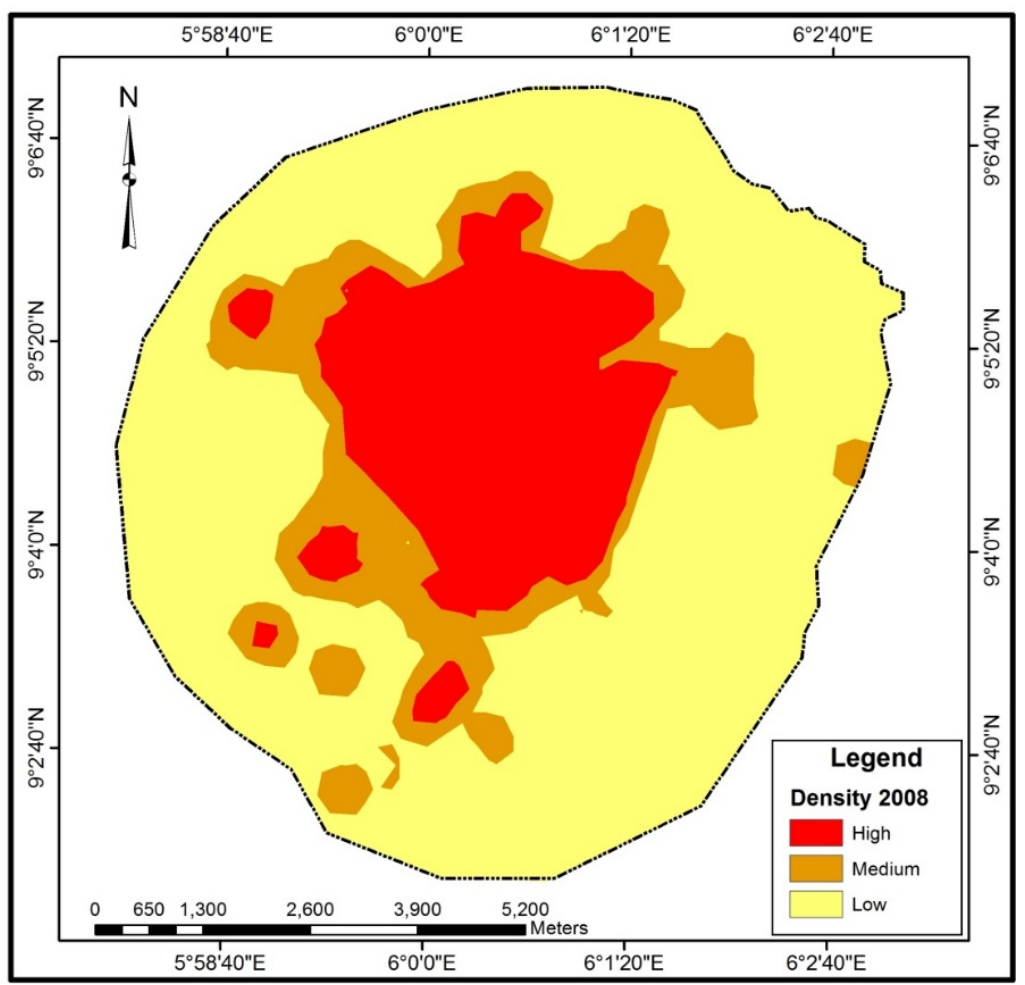

Fig. 6. Residential density classification for the year 2008 (Developed by the authors, 2020).

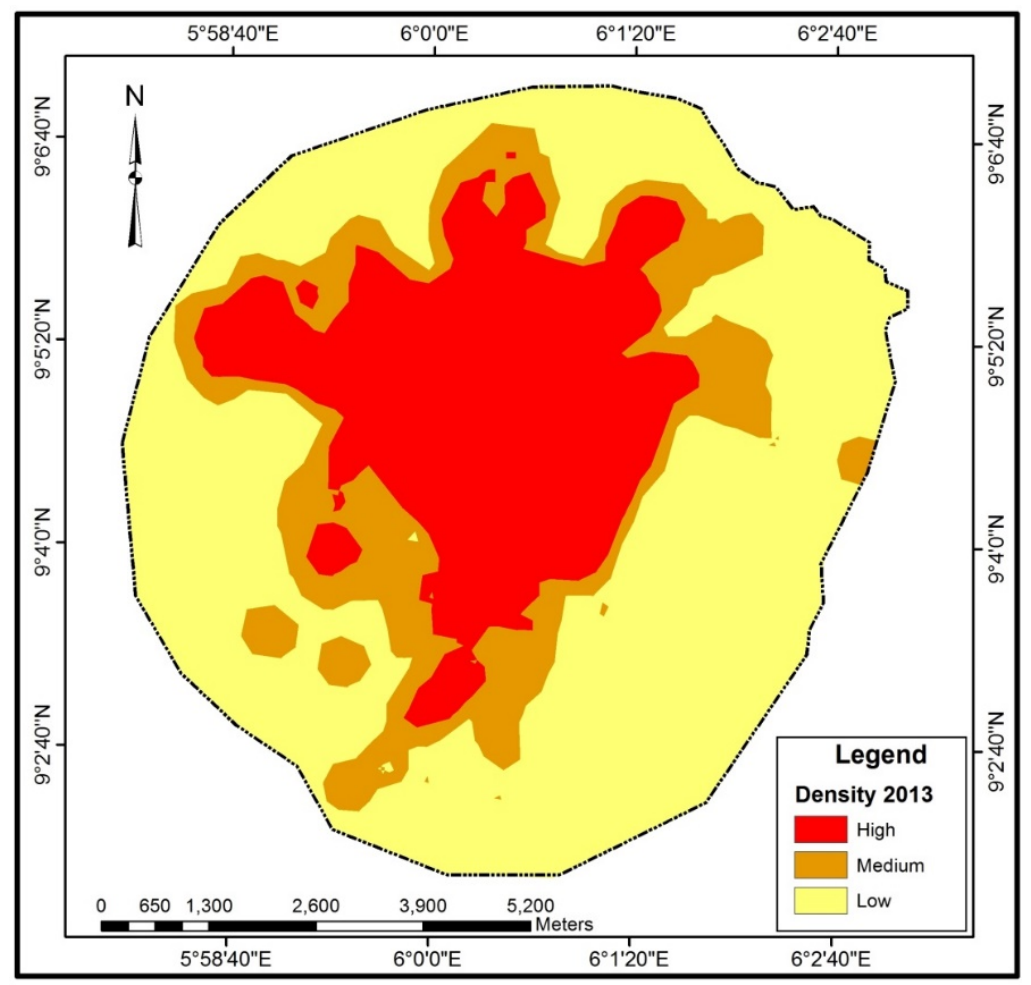

Fig. 7. Residential density classification for the year 2013 (Developed by the authors, 2020). 


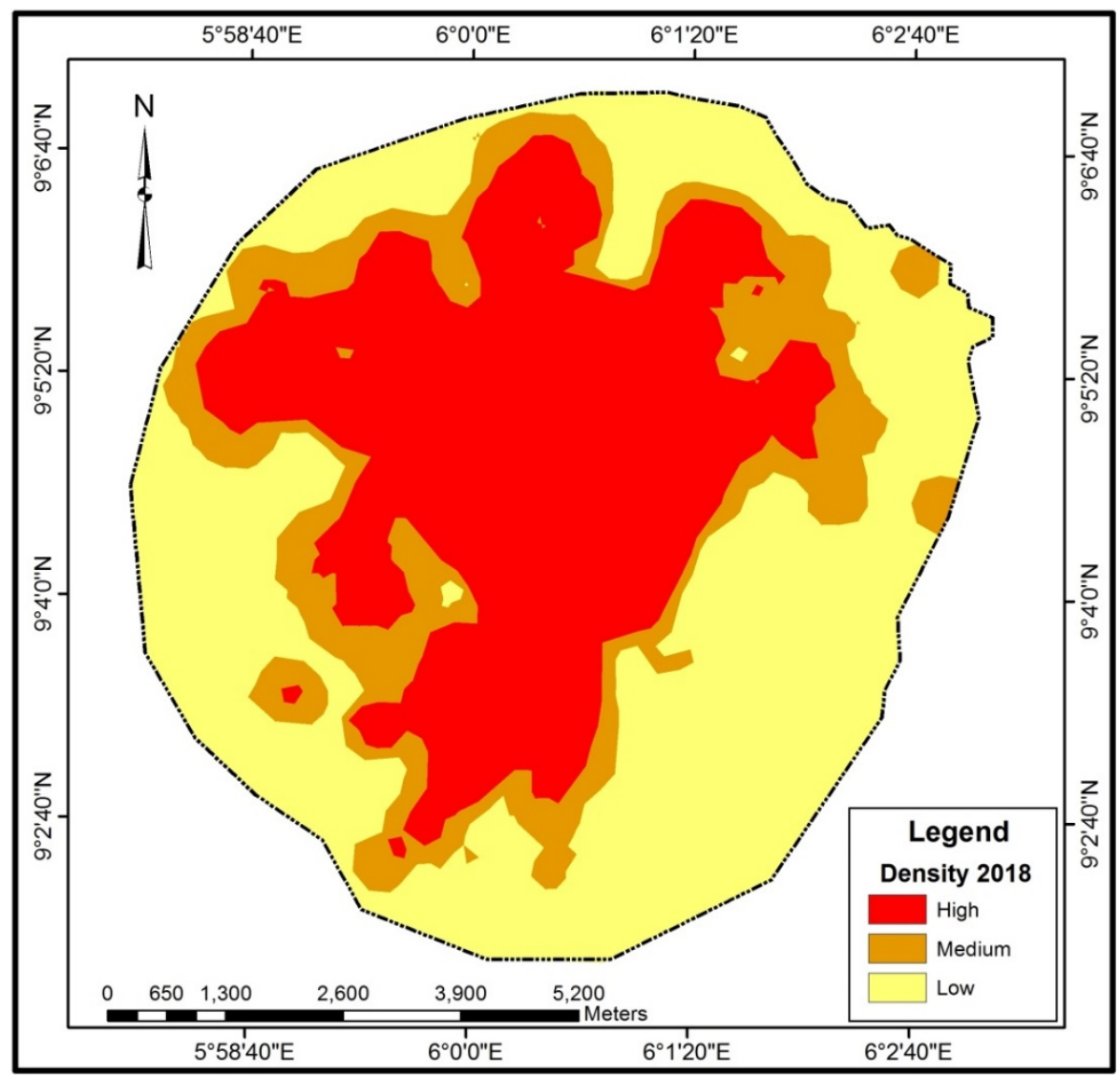

Fig. 8. Residential density classification for the year 2018 (Developed by the authors, 2020).

The residential density changes that occurred in the study area in the three different years under investigation were calculated and measured in $\mathrm{km}^{2}$ and percentage area coverage. This study revealed that in $2008,42.82 \mathrm{~km}^{2}(63.46 \%)$ of the total area was covered by the low density, followed by $10.15 \mathrm{~km}^{2}(15.04 \%)$ of medium density area, while the high density covered about $14.51 \mathrm{~km}^{2}(21.50 \%)$ of the total land area. In 2013, there was a great change where high density covered $27.16 \%$ of the total land area and medium-density area also increased in its area coverage to $17.93 \%$, while the low-density area decreased to about $54.91 \%$ from its initial $63.46 \%$ in 2008 . The town experienced great density changes between 2013 and 2018 where high density covered about $37.36 \%$ of the total area. However, the medium-density area experienced a drop of $17.78 \%$, while $44.86 \%$ of the total area was covered by the low-density area (Table 1).

The findings revealed a fast urban growth of the town and also indicated the need for urgent intervention to check the fast-growing unplanned urban densification. 
Table 1. Residential Density Changes for 2008, 2013 and 2018 (Developed by the authors, 2020)

\begin{tabular}{|l|c|c|c|c|c|c|}
\hline \multirow{2}{*}{ Density Type } & \multicolumn{2}{|c|}{$\mathbf{2 0 0 8}$} & \multicolumn{2}{c|}{$\mathbf{2 0 1 3}$} & \multicolumn{2}{c|}{2018} \\
\cline { 2 - 7 } & $\mathbf{k m}^{\mathbf{2}}$ & $\mathbf{\%}$ & $\mathbf{k m}^{\mathbf{2}}$ & $\mathbf{\%}$ & $\mathbf{k m}^{\mathbf{2}}$ & $\mathbf{\%}$ \\
\hline High density & 14.51 & 21.50 & 18.33 & 27.16 & 25.21 & 37.36 \\
\hline Medium density & 10.15 & 15.04 & 12.10 & 17.93 & 12.00 & 17.78 \\
\hline Low density & 42.82 & 63.46 & 37.05 & 54.91 & 30.27 & 44.86 \\
\hline
\end{tabular}

The trends in the residential changes presented in Fig. 9 indicate a sharp drop in low-density total area coverage, while the high-density area experiences rise in the curve, which is expected to continue if nothing is done to control the organic growth of the town. However, the medium density curve flattenned between 2013 and 2018. The findings indicate that high-density areas overtook both low- and medium-density areas. Therefore, without any policy formulation and implementation to guide or control this ugly development, it may be difficult to conduct any urban renewal or upgrade sooner or later.

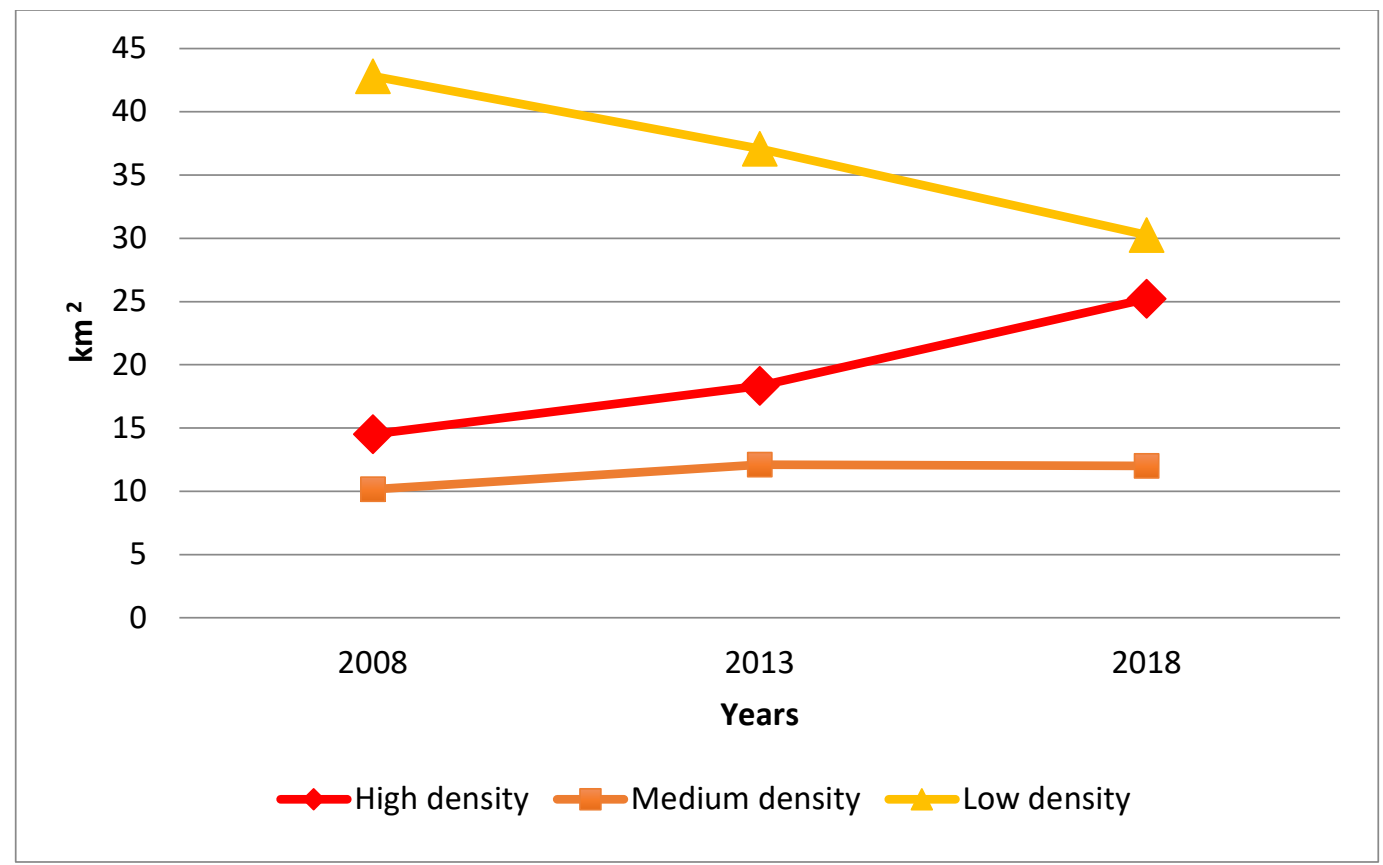

Fig. 9. Trend in residential density changes for 2008, 2013 and 2018 (Developed by the authors, 2020). 


\section{DISCUSSION}

The study area experienced great density changes between 2013 and 2018 where high-density area covered about $21.50 \%$ of the total area in 2008 and $37.36 \%$ in 2018 . However, the medium-density area experienced a drop from $17.93 \%$ in 2013 to $17.78 \%$ in 2018 , while only $44.86 \%$ of the total area was covered by the low-density area in 2018 from $63.46 \%$ in 2008 . The trends in the residential changes indicate a sharp drop in low-density total area coverage, while the high-density area experiences rise in the curve, which is expected to continue if nothing is done to control the organic growth of the town. However, the medium density curve flattenned between 2013 and 2018.

This pattern of densification process is in line with the urban economic theory for monocentric open cities that experience population growth and decreasing commuting costs (Antoniucci \& Marella, 2018). As residential densities increase along with the urban-rural gradient, the observed increase in residential densities associated with the presence of restrictive spatial planning is also in line with expectations from the urban economic theory. However, in the study area, restrictive spatial planning is not in place. This analysis provides some empirical underpinning for city structures in line with the monocentric model of Alonso (1964). Similar patterns were observed by Broitman and Koomen (2015) who studied residential density change by focussing on densification and urban expansion, i.e., in urban development, the number of housing units increases towards the city centre. Wang et al. (2019) found similar importance for the growth centres in their analysis of urban densification dynamics and future modes in Southeastern Wisconsin, the USA. However, it can be inferred from the research findings that residential development occurs more in areas that are rich in amenities but in this study, it occurs more in the areas with less or no physical planning regulations.

Findings of this study also show a transition of high density towards the urban fringe without development control, which is expected to continue if nothing is done to cushion the menace. There is clear evidence of organic urban transformation which takes its root from the traditional urban centres located at the core area of the town. The spatiotemporal analysis as revealed in the study implies fast urban growth in Bida. It also indicates that low- and medium-density areas were overtaken by the high-density area within few years. This form of development is argued to be a form of unplanned or uncontrolled urban densification. As such, there is a critical need for policy formulation and implementation of development control; otherwise, it may be difficult to carry out any intervention or upgrade such as urban renewal.

\section{CONCLUSIONS}

In the study, it was observed that there was an increase in high- and mediumdensity areas and a sharp drop in low-density area between 2008 and 2018, where high-density area increased in the curve, while the medium-density curve flattened, and the low-density area reduced. The residential density increased along the urban- 
rural gradient, which was in line with the monocentric model of Alonso, thereby causing a transition of open spaces and low-density areas to medium- and highdensity areas which could be attributed to poor restrictive spatial planning in the study area. Hence, the study area continues to grow in an organic urban morphological structure, which requires urgent physical planning interventions. The study, therefore, suggests rational densification (planned densification) in urban development, which can curb the increasing residential density that reduces green and open spaces and can also reduce its negative implications on the environment. Conducting planned densification, urban managers should propose a new development plan for the affected areas by converting certain areas from lowdensity to medium-density areas and medium-density to high-density areas, where open spaces, green areas, waterfronts, and recreational areas are put into critical consideration.

\section{REFERENCES}

Ahlfeldt, G. (2011). If Alonso Was Right: Modeling Accessibility and Explaining The Residential Land Gradient. Journal of Regional Science, 51(2), 318-338. https://doi.org/10.1111/j.14679787.2010.00694.x

Alexander, E. R. (1993). Density Measures: A Review and Analysis. Journal of Architectural and Planning Research, 10(3), 181-202.

Alonso, W. (1964). Location and Land Use: Toward a General Theory of Land Rent. Publication of the Joint Center for Urban Studies. Harvard University Press.

Amer, M., Mustafa, A., Teller, J., Attia, S., \& Reiter, S. (2017). A Methodology to Determine the Potential of Urban Densification through Roof Stacking. Sustainable Cities and Society, 35, 677-691. https://doi.org/10.1016/j.scs.2017.09.021

Antoniucci, V., \& Marella, G. (2018). Is Social Polarization Related to Urban Density? Evidence from the Italian Housing Market. Landscape and Urban Planning, 177, 340-349. https://doi.org/10.1016/j.landurbplan.2017.08.012

Broitman, D., \& Koomen, E. (2015). Residential Density Change: Densification and Urban Expansion. Computers, Environment and Urban Systems, 54, 32-46. https://doi.org/10.1016/j.compenvurbsys.2015.05.006

Broitman, D., \& Koomen, E. (2019). The Attraction of Urban Cores: Densification in Dutch City Centres. Urban Studies, 004209801986401. https://doi.org/10.1177/0042098019864019

Chandrabose, M., Owen, N., Giles-Corti, B., Turrell, G., Carver, A., \& Sugiyama, T. (2019). Urban Densification and 12-Year Changes in Cardiovascular Risk Markers. Journal of the American Heart Association, 8(15). https://doi.org/10.1161/JAHA.119.013199

Chhipi-Shrestha, G., Hewage, K., \& Sadiq, R. (2017). Impacts of Neighborhood Densification on Water-Energy-Carbon Nexus: Investigating Water Distribution and Residential Landscaping System. Journal of Cleaner Production, 156, 786-795. https://doi.org/10.1016/j.jclepro.2017.04.113

Curie, F., Perret, J., \& Ruas, A. (2010). Simulation of Urban Blocks Densification. In 13th Agile International Conference on Geographic Information Science.

de Oliveira e Sousa, M. N. P., \& Celani, M. G. C. (2018). Towards Urban Densification: Parametric Modeling of Possible Scenarios for Urban Mobility. Blucher Design Proceedings, 415-422. https://doi.org/10.5151/sigradi2018-1269

Delmelle, E., Zhou, Y., \& Thill, J.-C. (2014). Densification without Growth Management? Evidence from Local Land Development and Housing Trends in Charlotte, North Carolina, USA. Sustainability, 6(6), 3975-3990. https://doi.org/10.3390/su6063975 
Duan, S., Luo, Z., Yang, X., \& Li, Y. (2019). The Impact of Building Operations on Urban Heat/Cool Islands under Urban Densification: A Comparison between Naturally-Ventilated and Air-Conditioned Buildings. Applied Energy, 235, 129-138.

https://doi.org/10.1016/j.apenergy.2018.10.108

Fujita, M. (1989). Urban Economic Theory: Land Use And City Size. Cambridge University Press.

Fujita, M. (2010). The Evolution of Spatial Economics: From Thünen to the New Economic Geography. Japanese Economic Review, 61(1), 1-32. https://doi.org/10.1111/j.14685876.2009.00504.x

Ghadami, M., \& Newman, P. (2019). Spatial Consequences of Urban Densification Policy: Floorto-Area Ratio Policy in Tehran, Iran. Environment and Planning B: Urban Analytics and City Science, 46(4), 626-647. https://doi.org/10.1177/2399808317722168

Gulyani, S., Talukdar, D., \& Bassett, E. M. (2018). A Sharing Economy? Unpacking Demand and Living Conditions in the Urban Housing Market in Kenya. World Development, 109, 57-72. https://doi.org/10.1016/j.worlddev.2018.04.007

Gwamna, E. S., Wan Yusoff, W. Z., \& Ismail, M. F. (2015). Determinants of Land Use and Property Value. Advanced Science Letters, 21(5), 1150-1153. https://doi.org/10.1166/asl.2015.6065

Haaland, C., \& van den Bosch, C. K. (2015). Challenges and Strategies for Urban Green-Space Planning in Cities Undergoing Densification: A Review. Urban Forestry \& Urban Greening, 14(4), 760-771. https://doi.org/10.1016/j.ufug.2015.07.009

Jiao, L. (2015). Urban Land Density Function: A New Method to Characterize Urban Expansion. Landscape and Urban Planning, 139, 26-39. http://dx.doi.org/10.1016/j.landurbplan.2015.02.017

Kulish, M., Richards, A., \& Gillitzer, C. (2012). Urban Structure and Housing Prices: Some Evidence from Australian Cities: Urban Structure and Housing Prices. Economic Record, 88(282), 303-322. https://doi.org/10.1111/j.1475-4932.2012.00829.x

Kyttä, M., Broberg, A., Tzoulas, T., \& Snabb, K. (2013). Towards Contextually Sensitive Urban Densification: Location-Based softGIS Knowledge Revealing Perceived Residential Environmental Quality. Landscape and Urban Planning, 113, 30-46. https://doi.org/10.1016/j.landurbplan.2013.01.008

Leffers, D., \& Ballamingie, P. (2013). Governmentality, Environmental Subjectivity, and Urban Intensification. Local Environment, 18(2), 134-151. https://doi.org/10.1080/13549839.2012.719016

León Canales, J., Vicuña del Río, M., \& Gubler, A. (2019). Increasing Tsunami Risk through Intensive Urban Densification in Metropolitan Areas: A Longitudinal Analysis in Viña del Mar, Chile. International Journal of Disaster Risk Reduction, 101312. https://doi.org/10.1016/j.ijdrr.2019.101312

Lima, I., Scalco, V., \& Lamberts, R. (2019). Estimating the Impact of Urban Densification on HighRise Office Building Cooling Loads in a Hot and Humid Climate. Energy and Buildings, 182, 30-44. https://doi.org/10.1016/j.enbuild.2018.10.019

Lin, B., Meyers, J., \& Barnett, G. (2015). Understanding the Potential Loss and Inequities of Green Space Distribution with Urban Densification. Urban Forestry \& Urban Greening, 14(4), 952958. https://doi.org/10.1016/j.ufug.2015.09.003

Loibl, W., Etminan, G., Österreicher, D., Ratheiser, M., Stollnberger, R., Tschannett, S., Tötzer, T., Vuckovic, M. \& Walal, K. (2019). Urban Densification and Urban Climate Change-Assessing Interaction through Densification Scenarios and Climate Simulations. Proc. of the REAL CORP.

Magliocca, N., Safirova, E., McConnell, V., \& Walls, M. (2011). An Economic Agent-Based Model of Coupled Housing and Land Markets (CHALMS). Computers, Environment and Urban Systems, 35(3), 183-191. https://doi.org/10.1016/j.compenvurbsys.2011.01.002

Manganelli, B., \& Murgante, B. (2017). The Dynamics of Urban Land Rent in Italian Regional Capital Cities. Land, 6(3), 54. https://doi.org/10.3390/land6030054

Medayese, M., Martins, V. E., \& Abdrazack, N. T. (2015). Density. In L. Egunjobi (Ed.), Contemporary Concepts in Physical Planning (1st ed., vol. 1, pp. 263-290). University of Ibadan. 
Mohammed, J. K., \& Sulyman, A. O. (2019). Spatio-Temporal Analysis of Bida Housing Market Using Geographic Information System. In L. T. Ajibade, N. B. Tanimowo, G. Amuda-Yusuf, \& N. A. Bello (Eds.), The Proceedings of International Conference of Environmental Sciences (pp. 306-316).

Ribault, C., Bouquerel, M., Brun, A., Schumannb, M., Rusaouën, G., \& Wurtz, E. (2017). Assessing Tools Relevance for Energy Simulation at the Urban Scale: Towards Decision-Support Tools for Urban Design and Densification. Energy Procedia, 122, 871-876.

https://doi.org/10.1016/j.egypro.2017.07.452

Schmidt-Thomé, K., Haybatollahi, M., Kyttä, M., \& Korpi, J. (2013). The Prospects for Urban Densification: A Place-Based Study. Environmental Research Letters, 8(2), 025020. https://doi.org/10.1088/1748-9326/8/2/025020

Shahtahmassebi, A. R., Song, J., Zheng, Q., Blackburn, G. A., Wang, K., Huang, L. Y., Pan, Y., Moore, N., Shahtahmassebi, G., Haghighi, R. S., \& Deng, J. S. (2016). Remote sensing of impervious surface growth: a framework for quantifying urban expansion and re-densification mechanisms. International Journal of Applied Earth Observation and Geoinformation, 46, 94112. https://doi.org/10.1016/j.jag.2015.11.007

Ståhle, A. (2008). Compact Sprawl: Exploring Public Open Space and Contradictions in Urban Density. School of Architecture, KTH.

Treija, S., Bratuškins, U., \& Koroḷova, A. (2018). Urban Densification of Large Housing Estates in the Context of Privatisation of Public Open Space: The Case of Imanta, Riga. Architecture and Urban Planning, 14(1), 105-110. https://doi.org/10.2478/aup-2018-0014

Vergnes, A., Pellissier, V., Lemperiere, G., Rollard, C., \& Clergeau, P. (2014). Urban Densification Causes the Decline of Ground-Dwelling Arthropods. Biodiversity and Conservation, 23(8), 1859-1877. https://doi.org/10.1007/s10531-014-0689-3

Vuckovic, M., Loibl, W., Tötzer, T. \& Stollnberger, R. (2019). Potential of Urban Densification to Mitigate the Effects of Heat Island in Vienna, Austria. Environments, 6(7), 82. https://doi.org/10.3390/environments6070082

Waddell, P. (2000). A Behavioral Simulation Model for Metropolitan Policy Analysis and Planning: Residential Location and Housing Market Components of Urbansim. Environment and Planning B: Planning and Design, 27(2), 247-263. https://doi.org/10.1068/b2627

Wang, L., Omrani, H., Zhao, Z., Francomano, D., Li, K., \& Pijanowski, B. (2019). Analysis on Urban Densification Dynamics and Future Modes in Southeastern Wisconsin, USA. PLOS ONE, 14(3), 1-22. https://doi.org/10.1371/journal.pone.0211964

Wolff, M., Haase, A., Haase, D., \& Kabisch, N. (2017). The Impact of Urban Regrowth on the Built Environment. Urban Studies, 54(12), 2683-2700. https://doi.org/10.1177/0042098016658231

Xiao, Y. (2017). Urban Morphology and Housing Market. Springer Singapore. https://doi.org/10.1007/978-981-10-2762-8

\section{AUTHORS' SHORT BIOGRAPHIES}

Jibrin Katun Mohammed attended Abubakar Anike Model Primary School, Bida, Nigeria from 1991 to 1996. He obtained Senior Secondary School Certificate in 2003. He obtained a Bachelor degree of Technology in Estate Management and Valuation from the Federal University of Technology, Minna in 2014. Currently, he is a Postgraduate student at Master (M. tech.) level, Housing and Urban Renewal in Urban and Regional Planning Department, Federal University of Technology, Minna. J. K. Mohammed worked as a GIS consultant at the Department of Estate Management and Valuation and Department of Urban and Regional Planning, the Federal Polytechnic, Bida between 2016 and 2019. He is currently a Lecturer at the Department of Estate Management and Valuation, Federal Polytechnic, Bida, Nigeria.

Address: Department of Estate Management and Valuation, Federal Polytechnic, Bida, Nigeria.

Email: jibrinkatun@gmail.com

ORCID iD: https://orcid.org/0000-0002-3365-230X 
Dr Aremu Olanrewaju Sulyman had his first degree in Geography from Ahmadu Bello University, Zaria and Master's degree in Urban and Regional Planning from the University of Ibadan, Ibadan and $\mathrm{PhD}$ in Geography from the University of Ilorin, Ilorin. He is currently an Associate Professor at the Department of Urban and Regional Planning, Federal University of Technology, Minna, Nigeria. Professionally, Dr. Sulyman is a corporate member of the Nigerian Institute of Town Planners and a Registered Town Planner with the Town Planners Registration Council.

Address: Department of Urban and Regional Planning, Federal University of Technology, Minna, Nigeria.

Email: sulymanlance@gmail.com

Abdullahi Alhaji Aliyu attended Government Secondary School, Lemu, Niger State, Nigeria between 1980 and 1985 for his secondary education and later between 1986 and 1988 for his Advanced Level (A/Level, Interim Joint Matriculation Board Examination). He is a graduate of Geography from the Ahmadu Bello University, Zaria, Nigeria (1992). He obtained a Master of Technology degree in Urban and Regional Planning from the Federal University of Technology, Minna, Nigeria in 2012. Currently, he is a PhD degree student in Urban and Regional Planning at the same university. A. A. Aliyu is currently a Principal Lecturer at the Department of Urban and Regional Planning, the Federal Polytechnic, Bida, Nigeria from 2011 to date. His areas of research interests include housing, urban governance, environmental impact assessment and tourism and recreation planning; areas in which he has published extensively in both local and international journals. He is a member of the Nigerian Institute of Town Planners and Registered Town Planner with Town Planners Registration Council of Nigeria.

Address: Department of Urban and Regional Planning, Federal Polytechnic, Bida, Nigeria.

Email: aliyubadul777@gmail.com

ORCID iD: https://orcid.org/0000-0002-9930-5837 